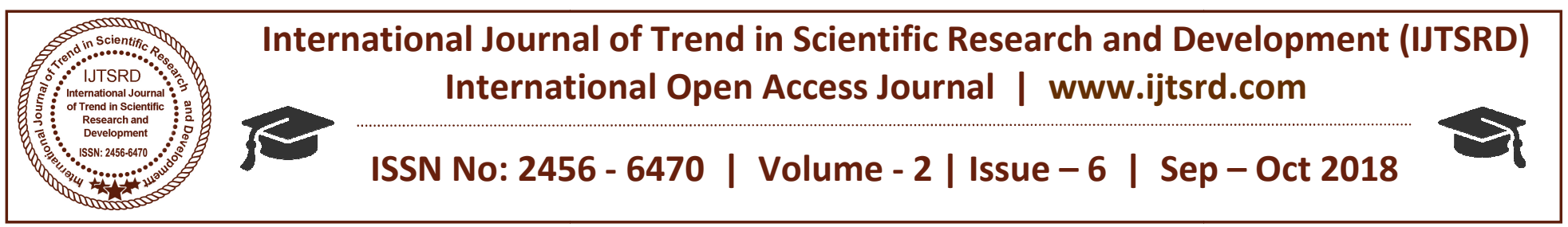

\title{
Enhanceing the Properties of Soil by using Synthetic Polypropylene
}

\author{
Amjed Ali Khan ${ }^{1}$, Er Anu ${ }^{2}$ \\ ${ }^{1}$ M.Tech Student, ${ }^{2}$ Assistant Professor \\ Department of Civil Engineering, GGGI, Dinarpur Ambala, Haryana, India
}

\begin{abstract}
Soil is the cheapest and easily available building material, but it is poor in mechanical properties such as bearing strength of soil. Research workers are continuously trying to improve the mechanical properties of soil, reinforced earth is a construction material having soil fill, toughen by addition of rods, bars, fibers, or nets that make a bond with the soil by mode of frictional resistance and act as a clear mass. It is used in many applications retaining structures, embankments etc. On comparing soil properties by adding different percentage of fibres by soil's dry weight by performing direct shear test and standard procter test different properties are carried out. As we add polypropylene fiber in the soil maximum dry density decreases and there is the increase in optimum moisture content direct shear test that performed on soil shows the decrement in the value of internal friction and increase in the value of cohesion. Increase in Unconfined compression strength
\end{abstract}

Keyword: Direct shear test, standard Procter test, polypropylene fibre, Unconfined compression test.

\section{INTRODUCTION}

a new construction material formed by taking into account the combination of reinforcement and earth known as earth reinforcement. earth reinforcement is made by membership of frictional soil and the elements that resists tension in the manner of mats, sheets, strips and nets of metal, fiber with plastic reinforcement or synthetic fabric and placed in soil mass in such a manner as to decrease or compress the tensile strain which may produce under boundary and gravity forces. Soil gives foundation for the structure and its achievement depends upon native environment conditions. Soft clay layers are often set unable to take the load transferred from the structures above to the foundation. Soil reinforcement has been in popularity in crude form since earle times. Some of the current historical records bear evidence to use the technique of earth reinforcement (Jones 1978). No balanced study of soil reinforcement had been made till a French engineer, Henri Vidal, gives his analysis on reinforcement of soil in 1968 and initiated the use of the term "Reinforced Earth" A multiplicity of earth structures have been made in different parts of the world in last two centuries by using reinforced earth principle. Bridge abutments, Highway embankments earth dams and retaining walls with sharp slopes have been built using distinct types of reinforcements. Experimental results prepared by various analysers Mc-Gown et al (1978), Verma and Char(1978); Gray and Maher (1989) have shown that fiber reinforcement causes significant improvement in strength and stiffness of sand. Maher and Gray (1990), Al Refeai (1991) have announced that with increase in fiber content the strength of reinforced sand raises, soil fiber surface friction and aspect ratio. AlHussaini (1977) announced the results of field experimental studies on a fabric reinforced earth wall. The reinforced sheets used were heavy duty nylon fabric coated with neoprene. Panels of Aluminum were used as membrane elements. Hoare (1979) reviewing the out come of a chains of laboratory compression and CBR tests on a sandy gravel reinforced with randomly apportioned synthetic fibers less than $2 \%$ by weight seen that the appearance of fibers elevated the angle of internal friction and ductility of the soil especially at low confining stress. Here in this study soil stabilization is done by using arbitrarily distributed polypropylene fibers recived from waste materials. The improvement in the parameters of shear strength pointed on the side by side studies haave been taken out by using distinct ways of measurement of shear strength. 


\section{EXPERIMENTAL WORK}

\subsection{Material}

\subsubsection{Soil}

The soil sample taken in this study is from a local farm land of jammu city. The soil had some properties of expensive soil such as black cotton soil

Geotechnical properties of soil used in study

\begin{tabular}{|c|c|c|}
\hline $\begin{array}{c}\text { Sr. } \\
\text { No }\end{array}$ & Particulars & Value \\
\hline 1 & Specific gravity & 2.61 \\
\hline 2 & Liquid limit \% & 57 \\
\hline 3 & Plastic limit \% & 29 \\
\hline 4 & Plasticity index \% & 28 \\
\hline 5 & Optimum moisture content $(\%)$ & 21.2 \\
\hline 6 & Maximum dry density $\left(\mathrm{gm} / \mathrm{cm}^{3}\right)$ & 1.54 \\
\hline 7 & Cohesion $\left(\mathrm{kN} / \mathrm{m}^{2}\right)$ & 30 \\
\hline 8 & Angle of internal friction $($ Degrees $)$ & 17 \\
\hline 9 & $\begin{array}{r}\text { Unconfined compressive } \\
\text { strength }\left(\mathrm{Kg} / \mathrm{cm}^{2}\right)\end{array}$ & 3.5 \\
\hline
\end{tabular}

\subsection{2 polypropylene fiber(ppf)}

The index and strength parameters of polypropylene fiber is shown below.

\begin{tabular}{|c|c|}
\hline Behaviour & Value \\
\hline Fibre type & Single fibre \\
\hline unit weight & $0.91 \mathrm{~g} / \mathrm{cm}^{3}$ \\
\hline Average diameter & $0.34 \mathrm{~mm}$ \\
\hline Average length & $12 \mathrm{~mm}$ \\
\hline Breaking tensile strength & $350 \mathrm{mpa}$ \\
\hline Modulus of elasticity & $3500 \mathrm{mpA}$ \\
\hline Fusion point & $165^{\circ} \mathrm{c}$ \\
\hline Burning point & $590^{\circ} \mathrm{c}$ \\
\hline Acid and alkali resistance & Very good \\
\hline Dispersibility & Excellent \\
\hline
\end{tabular}

\section{LABORATORY TESTS}

Experimental investigation shows in depth the process of experimental work taken out to study the nature of of randomly distributed polypropylene fiber reinforced soil. The results carried out by standard procter test and unconfined compression test on soil with fiber reinforcement is studied. Geotechnical properties of soil taken in study are given in table 1 . For mixing of polypropylene fibre to the soil following steps are carried out. At their particular maximum dry density (MDD) and optimum moisture content (OMC), all the soil samples are compacted at their particular maximum dry density according to the standard procter compaction tests Amount of fiber in the soil is adopted by the equation given below:

Where,

$\rho \mathrm{f}=$ / fiber content ratio

$\mathrm{W}_{\mathrm{f}}=$ the fiber weight

$\mathrm{W}=$ air-dried soil weight

In the present study for the percentage of fiber reinforcement distinct values taken are $0,0.07,0.12$, and 0.20 .

1. In the setup of samples, if fiber is not used then, the atmospheric dried soil was combined with an amount of water that depends on the OMC of the soil.

2. If fiber reinforcement was used, the decided content of fibers was first mixed into the air-dried soil in small progression by hand, making sure that all the fibers were mixed effectively, so that a fairly uniform mixture is obtained, and then the needed water was added.

\section{RESULTS \& DISCUSSION}

\subsection{Proctor compaction test}

A clear connection is achieved by this experiment between the dry denseness of the soil and the water content of the soil. The experimental order consists of (i) cylindrical metal shaped (internal diameter- 10.15 $\mathrm{cm}$ and internal height-11.7 $\mathrm{cm}$ ), (ii) removable base plate, (iii) collar (5 $\mathrm{cm}$ effective height), (iv) rammer $(2.5 \mathrm{~kg})$. Compaction process helps in progressing the bulk density by moving out the air from the voids. The theory used in the experiment is that for any compactive deed, the dry density depends upon the moisture content in the soil. The maximum dry density (MDD) is retrieved when the soil is compacted at comparatively high moisture content and almost all the air is removed out, this moisture content is called optimum moisture content (OMC). 
We can obtain the OMC and MDD, by plotting the data from the experiment with water content as the abscissa and dry density as the ordinate

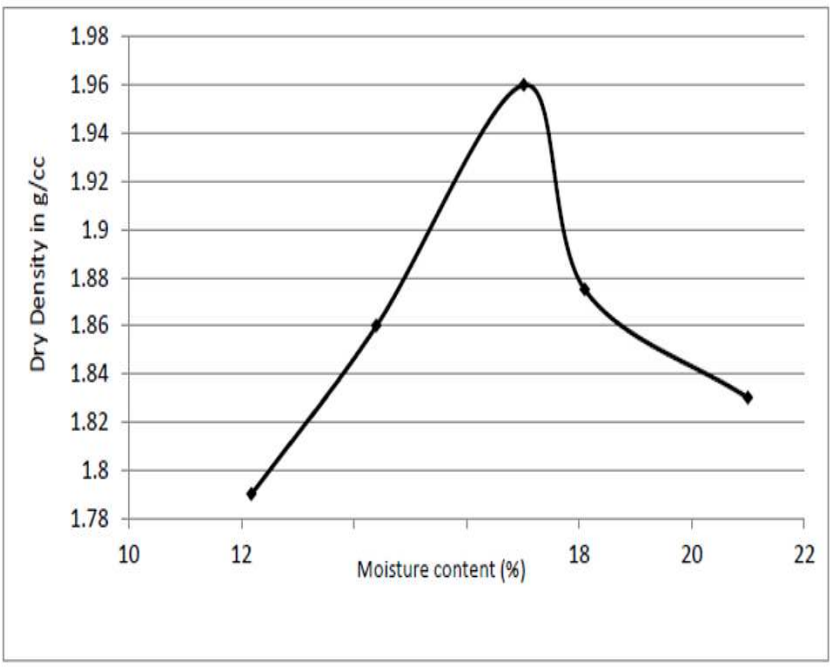

Proctor compaction test curve

\subsection{Direct shear test}

This test is performed to find out the cohesion (c) and the angle of internal friction $(\varphi)$ of the soil, these are known as shear strength parameters. The most important method to find out the properties of soil is direct shear test and it is needed when so ever any structure relies on the soil shearing opposition. The test is performed by taking the soil at OMC and MDD inside the shear box which is made up of two autonomous parts. An invariant normal load $(\varsigma)$ is applied to obtain one value of $\mathrm{c}$ and $\varphi$. Load parallel to earth (shearing load) is progressed at a constant rate and is applied until the failure point is reached. This load when divided with the area gives the shear strength ' $\tau$ ' for that specific normal load.

\subsection{Unconfined compression test.}

unconfined soil sample fails under simple compressive test is the unconfined compressive strength qu. The experimental apparatus consists of the compression device and dial gauges for load and deformation. The load was taken for distinct readings of strain dial gauge starting from $\varepsilon=0.005$ and increasing by 0.005 at each step. The rectified crosssectional area was calculated by dividing the area by $(1-\varepsilon)$ and then the compressive stress for each step was calculated by dividing the load with the rectified area.

The relationship between fiber content and shear strength parameters- (a) Cohesion and fiber content

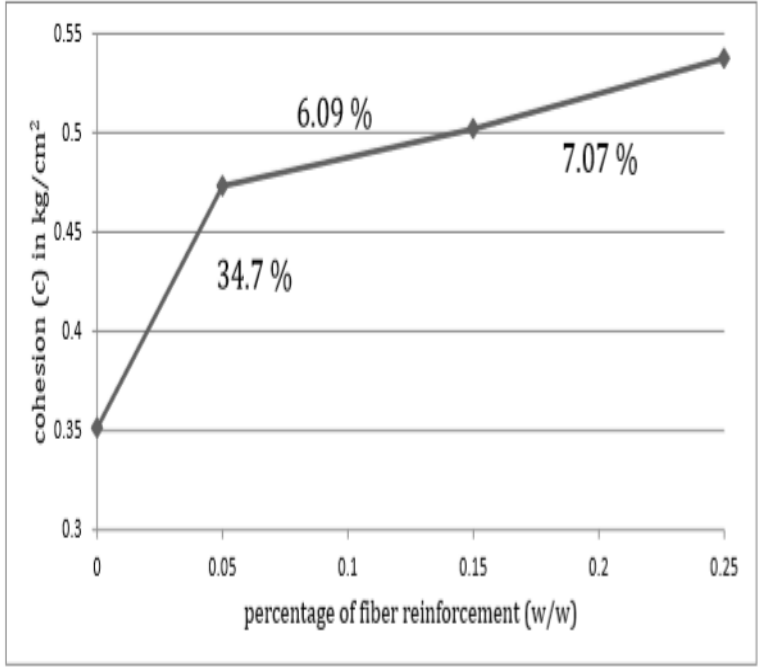

Fig- Relationship between cohesion and fiber content. (b) angle of internal friction and fiber content

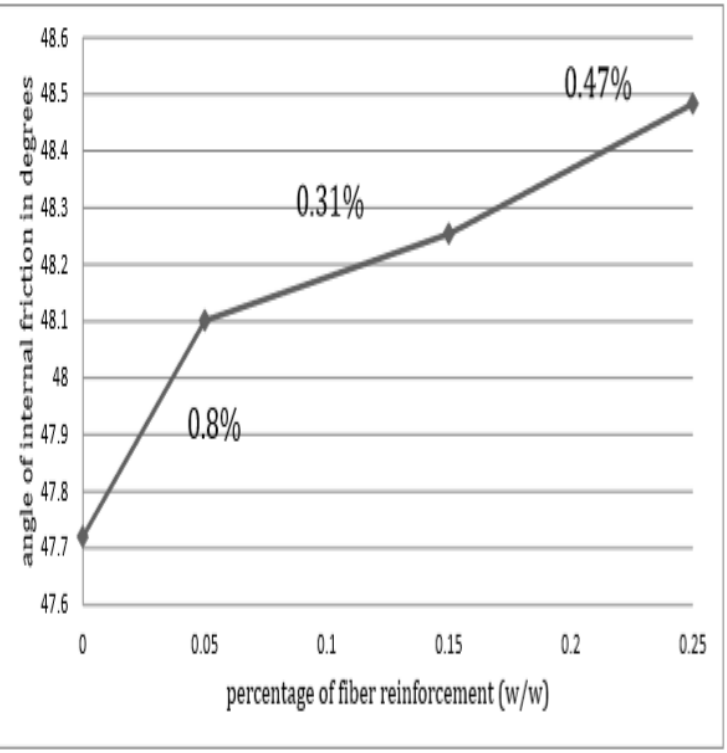

Fig- Relationship between angle of internal friction and fiber content

(c)Relationship between the UCS and fiber content

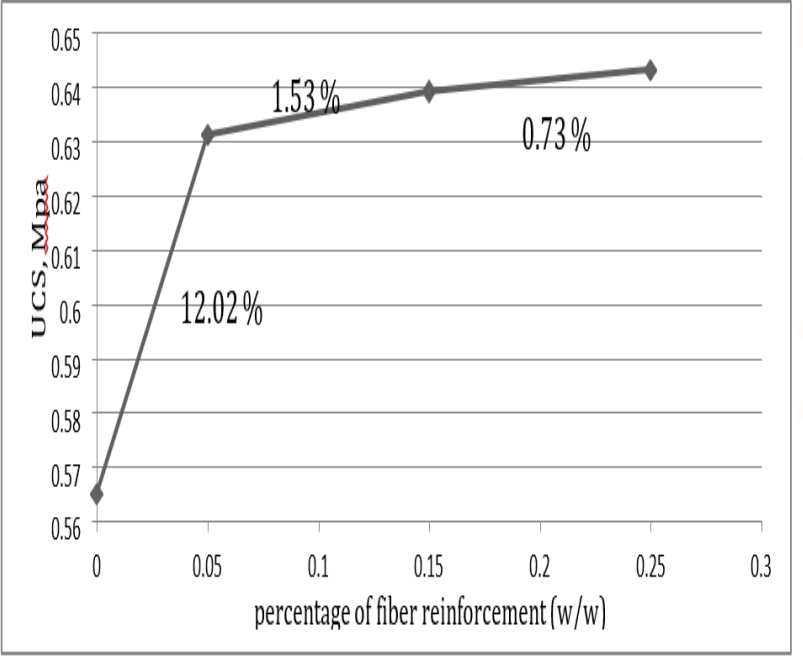

Fig- Relationship between UCS and fiber content 


\section{CONCLUSIONS}

1. Based on direct shear test on soil sample- 1 , with fiber reinforcement of $0.07 \%, 0.12 \%$ and $0.20 \%$, the increase in cohesion was found to be $12 \%, 5.6 \%$ and $4.80 \%$ respectively (illustrated in figure- 25 ). The increase in the internal angle of friction $(\varphi)$ was found to be $0.9 \%, 0.33 \%$ and $0.49 \%$ respectively (illustrated in figure-27). Since the net increase in the values of $\mathrm{c}$ and $\varphi$ were observed to be $19.6 \%$, from $0.325 \mathrm{~kg} / \mathrm{cm} 2$ to $0.3892 \mathrm{~kg} / \mathrm{cm} 2$ and $1.59 \%$, from 47.72 to 48.491 degrees respectively, for such a soil, arbitrarily distributed polypropylene fiber reinforcement is not recommended.

2. The results from the UCS test for reinforcements of $0.07 \%, 0.12 \%$ and $0.20 \%$, the unconfined compressive strength increase from the starting values are $12.02 \%, 1.53 \%$ and $0.73 \%$ respectively this is not a great increament and is not impressive on applying on soil sample-1

3. The shear strength parameters of soil sample- 2 were determined by direct shear test. Figure- 26 illustrates that the increase in the value of cohesion for fiber reinforcement of $0.07 \%, 0.12 \%$ and $0.20 \%$ are $37.8 \%, 7.21 \%$ and $8.12 \%$ respectively. Figure 27 illustrates that the increase in the internal angle of friction $(\varphi)$ was found to be $0.9 \%, 0.33 \%$ and $0.49 \%$ respectively. Thus, a net increase in the values of $\mathrm{c}$ and $\varphi$ were observed to be $53 \%$, from $0.3513 \mathrm{~kg} / \mathrm{cm}^{2}$ to $0.5775 \mathrm{~kg} / \mathrm{cm}^{2}$ and $15.04 \%$, from 27.82 to 33 degrees. Hance it is not preferred to use polypropylene for soil sample-1

4. The values of unconfined compressive strength show a net increment of $50.1 \%$ from $0.0692 \mathrm{MPa}$ to $0.1039 \mathrm{MPa}$ so the use of polypropylene for soil sample-2 is very effective

5. As a result, we concluded that soil with fiber reinforcement is considered as a very good soil improvement method specially in engineering fields which have unsound soil where it can act as a alternative to deep/raft foundations, which reduces both cost and energy. .

\section{REFERENCES}

1. S. A. Naeini and S. M. Sadjadi, (2008)," Effect of Waste Polymer Materials on Shear Strength of Unsaturated Clays", EJGE Journal, Vol 13, Bund $\mathrm{k}$,

2. Yetimoglu, T., Inanir, M., Inanir, O.E., 2005. A study on bearing capacity of orbotrarily distributed fiber-reinforced sand fills overlying soft clay. Geotextiles and Geomembranes 23 (2), 174-183.

3. Chaosheng Tang, Bin Shi, Wei Gao, Fengjun Chen, Yi Cai, 2006. Strength and mechanical behavior of short polypropylene fiber reinforced and cement stabilized clayey soil. Geotextiles and Geomembranes 25 (2007) 194-202.

4. Mahmood R. Abdi, Ali Parsapajouh, and Mohammad A. Arjomand,(2008)," Effects of Random Fiber Inclusion on Consolidation, Hydraulic Conductivity, Swelling, Shrinkage Limit and Desiccation Cracking of Clays", International Journal of Civil Engineering, Vol. 6, No. 4, (284-292).

5. Yadav Parit, MeenaKuldeep Kumar, (2011)"A comparative study in soil plasticity of Hall area and lecture complex area of NIT Rourkela" B.tech thesis, NIT, Rourkela.

6. IS: 2720(Part 2), 1973 Methods of Test for Soils, Determination of water content.

7. IS 2720(III/SEC-I): 1980 Methods of Test for Soils, Determination of specific gravity.

8. IS 2720(VII):1980 Methods of Test for Soils, Determination of water content dry density relation using light compaction.

9. IS 2720(XIII):1986 Methods of Test for Soils, direct shear test

10. IS 2720(X):1991 Methods of Test for Soils, determination of unconfined compression test.

11. IS 2720(IV):1985 Methods of Test for Soils, determination of grain size analysis.

12. Ground Improvement Techniques, December 18, 2008 [online] Available at: $<$ http://www.engineeringcivil.com >

13. Das B.M, 1992, Fundamentals of Soil Dynamics, Elsevier. 